\title{
Gender Difference in Learning Interest and Satisfaction with Social Media Applicability
}

\author{
Jon-Chao Hong \\ Department of Industrial Education \\ National Taiwan Normal University \\ Taipei, Taiwan \\ tcdahong@gmail.com
}

\author{
Wei-Yeh Hsu \\ Department of Industrial Education \\ National Taiwan Normal University \\ Taipei, Taiwan \\ vm21213@hotmail.com
}

\author{
Yi-Ling Chen \\ Department of Industrial Education \\ National Taiwan Normal University \\ Taipei, Taiwan \\ elainec.chn@gmail.com \\ Chin-Hao Hsu \\ Department of Industrial Education \\ National Taiwan Normal University \\ Taipei, Taiwan \\ henry780305@hotmail.com
}

\author{
Lianh-Ping Ma \\ Department of Industrial Education \\ National Taiwan Normal University \\ Taipei, Taiwan \\ ryohei-is-me@hotmail.com
}

\begin{abstract}
The difference in gender is often affected by the politics and the environment. A number of recent researches try to explore the impact of gender difference. As the internet becomes popularized, the way people learn is changed; many now learn through the internet. The present study unveiled the different types of video guitar learning lessons'influence on impulsive behavior, instrument learning self-efficacy, applicability, learning interest and user satisfaction. Online surveys were distributed through a guitar learning website, and a data of 177 containing 75 males and 42 females was obtained.
\end{abstract}

Previous researches show that females have an overall higher satisfaction and learning interest than males.However, the results of the present study showed that there was no gender difference in impulsive behavior, instrument learning self-efficacy and applicability when learning through video guitar learning lessons. In addition, the male user satisfaction and learning interest were significantly higher than that of the female.

Keywords-gender difference; self-efficacy; impulsive behavior; learning interest; user satisfaction

\section{INTRODUCTION}

The prosperity of internet and technology enable social media to provide platforms or online spaces for music media and picture uploads, and for users to interact. Von-Holzen\& Price[1] state that males have better computer skills andattitude than females. Papastergiou[2] illustrates that thereis no significant gender difference on the learning effects. So far, there is no consistency in the gender aspect of technology learning. As a result, the present study explored the effect of video guitar learning lessons on impulsive behavior, instrument learning self-efficacy, applicability, learning interest and satisfaction between genders.
Gender is one of the factors of individual difference. Individual difference is the distinct characteristics of a person, both mentally and physically. Gender is the socialized male and female characters, and is often related to the political and societal background. There are no stable gender roles, but are always developing and changing. Anderson[3] constructs a research on college students with non-computer majors and found that males have a greater attitude before and after computer lessons. Females usually have greater achievement in music than males.

Previous researches show inconsistent relationships between gender and impulsive behavior; thus, the present study explored the gender difference on video learning impulsive behavior. Overall, male interest in digital learning is higher than that of the female. Since different research participants and questions lead to different results, the present study focused on the gender influence on video learning self-efficacy.

\section{RESEARCH METHOD}

\section{A. Research Instruments}

The present study adapted the questionnaire survey, Kirk, Schutte\& Hine [4]Development and preliminary validation of an emotional self-efficacy scale, and Eysenck, Eysenck and Barrett [5]A revised version of the Psychoticism scale to assemble the research questionnaire. The questionnaire consists of two parts: the basic information and the evaluating constructs. Five-point Likert scale was used for the structural evaluation.

\section{B. Research Participants}

Questionnaire surveys were distributed through the online guitar learning website. A data of 120was obtained, eliminating the 3 invalid data to leave 144 for confirmatory factor analysis; the effective questionnaire return rate was 
97\%. Among them, there were 75 male and 42 female participants. 90 of them were a student and 27 of them were not a student. The values are shown in Table 1.

\section{RESUltS}

\section{A. Efficacy Analysis}

The AVE of the study ranged from .484-.695. All the values were above the suggested value of .5 except impulsive behavior and applicability. It implied that other than the applicability, the rest of the constructs had convergent validity.

\section{B. Reliability Analysis}

The study adapted Cronbach's a value and Fornell and Larcker[6] composite reliability, CR to evaluate the internal consistency of the models. According to Nunnally[7], a Cronbach's a over .7 is an acceptable value. According to Hair et al. [8], the value of CR should be over .7 to indicate internal consistency. As shown in Table 3, all the CR values were between .789-.919, surpassing .7, and the Cronbach's a were also greater than .7. It indicated the questionnaires were of satisfactory reliability, and that the constructs obtained internal consistency. Moreover, the means of the constructs were between a narrow range of 2.061-2.243, suggesting a low degree of dispersion.

TABLE I. INDEPENDENT T TEST

\begin{tabular}{|c|c|c|c|c|}
\hline & Gender & Mean & SD & t-test \\
\hline \multirow{2}{*}{$\begin{array}{l}\text { Instrument Learning } \\
\text { Self-Efficacy }\end{array}$} & M & 2.330 & .714 & .333 \\
\hline & $\mathrm{F}$ & 2.458 & .627 & .315 \\
\hline \multirow{2}{*}{ Applicability } & M & 2.150 & .581 & .154 \\
\hline & $\mathrm{F}$ & 1.982 & .652 & .169 \\
\hline \multirow{2}{*}{ User Satisfaction } & M & 2.139 & .574 & $.017 *$ \\
\hline & $\mathrm{F}$ & 1.857 & .650 & $.022 *$ \\
\hline \multirow{2}{*}{ Learning Interest } & M & 2.168 & .575 & $.001 * * *$ \\
\hline & $\mathrm{F}$ & 1.757 & .668 & $.001 * * *$ \\
\hline
\end{tabular}

\section{DISCUSSION AND CONCLUSION}

Previous researches on gender difference have no consistent conclusion, but gender difference is still a topic worth exploring. Liao, Che-Sheng[9] discovers that masculine individuals have substantially higher impulsive behavior than gender-neutral and feminine individuals. On the contrary, Caci[10] proposes a cross cultural research to assess the impulsivity and finds that there is little difference between genders. The present study also found no gender difference in impulsive behavior in video guitar learning.
In learning self-efficacy, researches show that male have a higher self-efficacy in mathematics and science whereas female have a higher self-efficacy in language Despite the implications, a number of researches find that females perform better than males in mathematics and sciences, and that males perform better than females in language ability. As a result, the gender difference in learning self-efficacy is still inconsistent. The present study found no gender difference in learning self-efficacy in video guitar learning, either.

Psychological factors can influence the applicability of computer learning. The present research found no gender difference in the applicability of video guitar learning lessons. It can also be due to the use of YouTube video lessons, that the website's popularity and familiarity are widespread.

In user satisfaction and learning interest, Chen, Hsiu-Yu [11] states that females have greater learning interest in music than their male counterparts. Females also have higher self-efficacy and expectation in music than males. The research indicates that the potential interest, text interest, mission interest and knowledge interest are higher in women than that in men. The present study showed that men had higher user satisfaction and learning interest than women, which corresponded to the gender difference in information technology, where there is a gender difference in usage and property. Generally, men use the internet resources for a longer period of time, and possess great interest than women [12] [13] [14].

The result of the study illustrated that impulsive behavior, instrument learning self-efficacy and applicability are similar between genders, but in user satisfaction and learning interest in video guitar learning, they were higher in males than in females; however, past researches illustrate that females have greater satisfaction and learning interest in music than males. In conclusion, the result of the study indicated that males had a higher satisfaction in video guitar learning, and the learning interest can then be increased.

\section{REFERENCES}

[1] R. L.Von Holzen, and R. V.Price,"Five year trends incomputer students' ttitudes and skill-levels," 1990

[2] M.Papastergiou,"Are computer science and informationtechnology still masculine fields? High school students'perceptions and career choices,"Computer and Education, vol.51, pp.594-608, 2008.

[3] C. A.Anderson, "Temperature and aggression: Ubiquitouseffects of heat on occurrence of human violence,"Psychological Bulletin, vol. 106, pp.74-96, 1989.

[4] B. A.Kirk,N. S.Schutte, and D. W.Hine,evelopment and preliminaryvalidation of an emotional self-efficacy scale,Australia : University of NewEngland, Armidale, NSW 2351, 2008.

[5] S. B. G. Eysenck, H. J.Eysenck, and P.Barrett, "A revised version of the Psychoticism scale,.”Person. individ. Diff, vol.6, pp.21-29, 1985.

[6] C.Fornell,D. F. Larcker,"Structural Equation Models with Unobservable Variables and Measurement Error,'Journal of Marketing Research, vol. 18, pp. 39-50, 1981.

[7] J.Nunnally,Psychometric Theory, New York: McGraw-Hill, 1978.

[8] J. E. Hair, R. E.Anderson, R. L. Tatham, and W. C.Blank, "MultivariateData Analysis, 5th ed.,"Prentice-Hall International Inc, 1998.

[9] C. S. Liao, Measuring for Propensity of Angry Driving and the Relationship with Personality and Gender-Role, 2009.

[10] H.Caci,L.Nadalet,F. J.Bayle,P.Robert, and P.Boyer,"Cross-cultural study of the Impulsiveness-Venturesomeness-empathy questionnaire (IVE-7),"Comprehensive Psychiatry, vol. 44, pp. 381-387, 2003. 
[11] N.S. Chen, and J. T. Yang, Theory and Practice of E-Learning. Taipei, DrMaster Press Co., Ltd, 2006.

[12] Pew Internet and American Life Project, "Tracking onlinelife: How women use the Internet to cultivate relationshipswith family and friends. Washington, DC, 2000.

[13] Pew Internet \& American Life Project, "A decade of adoption: How the internet has woven itself into American life,",2005.

[14] Pew Internet \& American Life Project, "Internet evolution, Internet penetration and impact," 2006. 